\title{
KEANEKARAGAMAN COLEOPTERA DAN ARANEIDA PERMUKAAN TANAH PADA BERBAGAI KONDISI SANITASI KEBUN KAKAO RAKYAT DI KABUPATEN KOLAKA TIMUR
}

\author{
DIVERSITY OF COLEOPTERA AND ARANEIDA ON THE GROUND OF COCOA \\ SMALLHOLDER PLANTATION WITH VARIOUS CONDITION OF SANITATION AT \\ EAST KOLAKA DISTRICT
}

\author{
Agung Yuswana ${ }^{(1)}$, Terry Pakki ${ }^{(2)}$, dan Mariadi ${ }^{(3)}$ \\ 1,2,3 Jurusan Proteksi Tanaman, Fakultas Pertanian Universitas Halu Oleo \\ (1) Corresponding author e-mail: agungyuswana@yahoo.com
}

\begin{abstract}
Abstrak
Penelitian Keanekaragaman Coleoptera dan Araneida di ekosistem Perkebunan Kakao Rakyat Kabupaten Kolaka Timur telah dilaksanakan pada bulan Oktober 2014 - Juni 2015. Tujuannya untuk mengevaluasi kepadatan relatif dan keanekaragaman Coleoptera dan Araneida permukaan tanah. Pengambilan sampel dilakukan di empat kondisi sanitasi kebun yang berbeda, yaitu tanpa sanitasi (TS), sanitasi bersih (SB), sanitasi pohon (SP), dan sanitasi lahan/seresah (SS), dengan luas masing-masing kebun sebesar satu hektar. Penelitian bersifat deskriptif - kuantitatif, dengan metode purposive, dan pengambilan sampel melalui penangkapan langsung dengan tangan, umpan serangga, dan perangkap. Hasilnya, dari ordo Coleoptera diperoleh enam famili yaitu Scarabaeidae, Scolytidae, Staphylinidae, Nitidulidae, Hydrophilidae, Dermestidae dan dari ordo Araneida juga diperoleh enam famili yaitu Salticidae, Thomisidae, Araneidae, Lycosidae, Arachnidae, dan Oxyopidae. Kepadatan relatif tertinggi ordo Coleoptera terdapat di kebun sanitasi bersih, yaitu famili Scolytidae 34,20\%, dengan indeks keragaman -0,16. Kepadatan relatif tertinggi dari ordo Araneida juga terdapat di kebun sanitasi bersih yaitu famili Lycosidae $5,20 \%$ dengan indeks keragaman $-0,018$.
\end{abstract}

Kata kunci : Kepadatan relatif, Indeks keanekaragaman, Coleoptera, Araneida

\begin{abstract}
The research diversity of Coleoptera and Araneida on the ground of Cocoa smallholder Plantation at East Kolaka was held in October 2014 - June 2015. The objective is to evaluate the relative density and diversity of Coleoptera and ground Araneida. Sampling was carried out in four different gardens sanitary conditions, i.e. without sanitation (TS), clean sanitary (SB), tree sanitary (SP), and land sanitary (SS) with each garden area of one hectare. The study was descriptive, using purposive sampling through direct capture by hand, insect baits and traps. The result, of the order coleoptera obtained six families (Scarabaeidae, Scolytidae, Staphylinidae, Nitidulidae, hydrophilidae, Dermestidae) and six families are Salticidae, Thomisidae, Araneidae, Lycosidae, Arachnidae, dan Oxyopidae of the order Araneida. In the cocoa field with clean sanitation, the highest relative density of the order coleoptera exhibited by the family Scolytidae $34.20 \%$, with a diversity index -0.16 and the highest relative density of the order araneida exhibited by the familiy Lycosidae $5.20 \%$ with a diversity index -0.018 .
\end{abstract}

Keywords: Relative density, Diversity index, Coleoptera, Araneida 


\section{PENDAHULUAN}

Penelitian keanekaragaman arthropoda di berbagai kondisi ekosistem baik ekosistem alami maupun agroekosistem, telah banyak dilakukan di berbagai wilayah di Indonesia. Khususnya di ekosistem perkebunan, penelitian yang terkait dengan keanekaragaman insekta di perkebunan kakao telah dilakukan di Jawa Barat, Jawa Tengah, DIY, Jawa Timur, Kalimantan Selatan, Kalimantan Barat, Kalimantan Timur, Sumatera utara, Sumatera Barat, Sumatera Selatan, Sulawesi Tengah, Sulawesi Selatan, Sulawesi Utara, Sulawesi Tenggara, Maluku, dan NTB . Hasil penelitian cukup bervariasi dalam hal indeks keanekaragaman, kerapatan relative, kekayaan spesies, kelimpahan, kemerataan, dan kesamaan. Keanekaragaman serangga pada umumnya sangat dipengaruhi oleh kompleksitas suatu lanskap, jenis vegetasi, iklim, garis lintang dan ketinggian tempat di atas permukaan laut, Atau topografi (Speigt, Hunter, Watt, 1999).

Dalam teknik budidaya kakao, sanitasi merupakan bagian dari aktivitas penting dalam pemeliharaan tanaman untuk menciptakan mikroklimat atau kondisi fisik lingkungan seperti suhu, kelembaban, intensitas cahaya, dan $\mathrm{pH}$ tanah, yang sesuai bagi pertumbuhan tanaman. Selain itu, sanitasi juga dapat menekan serangan hama dan penyakit tanaman kakao. Praktek sanitasi yang dilakukan oleh petani kakao di Sulawesi Tenggara dapat dikelompokkan menjadi empat kategori yaitu sanitasi pohon, sanitasi lahan, sanitasi bersih, dan tanpa sanitasi. Sanitasi pohon dilakukan dengan cara memangkas cabang, ranting yang rusak, memanen buah rusak terserang hama dan penyakit, menghilangkan cabang air, pohon tampak terawat, namun permukaan tanah di sekitar tanaman masih tertutup seresah, dan kulit buah tampak berserakan di dalam kebun.

Sanitasi lahan merupakan pembersihan permukaan tanah dari seresah, kulit buah, dan gulma di sekitar tanaman, dengan cara memasukkan material tersebut ke dalam lubang rorak atau got buntu yang dibuat di sekitar tanaman kakao. Kondisi permukaan tanah tampak bersih dari seresah, kulit buah, dan gulma, namun masih terlihat cabang, ranting, daun rusak, dan buah rusak terserang hama dan penyakit. Sanitasi bersih, petani melakukan sanitasi pohon dan sanitasi lahan, sehingga kondisi kebun tampak terawat dengan baik, tanaman bebas dari buah rusak, cabang atau ranting rusak, dan permukaan tanah di sekitar tanaman bebas dari seresah, kulit buah, dan gulma. Tanpa sanitasi, petani tidak melakukan perawatan kebun, tidak 
melakukan sanitasi pohon dan sanitasi lahan, sehingga kebun tampak kotor dan relative gelap. Perbedaan praktek sanitasi kebun kakao menyebabkan terjadinya perbedaan kondisi fisik lingkungan kebun seperti suhu, kelembaban, intensitas cahaya, $\mathrm{pH}$ tanah, dan diduga berpengaruh terhadap keanekaragaman arthropoda tanah di ekosistem kakao, oleh karena itu menjadi penting untuk mengkaji lebih mendalam tentang keanekaragaman,kekayaan spesies, kerapatan, kemelimpahan, kemerataan, dan kesamaan spesies.

Tulisan ini merupakan bagian dari suatu kajian penelitian keanekaragaman Arthropoda di ekosistem kakao, khusus memaparkan kajian tentang kerapatan relative dan keanekaragaman coleoptera dan araneida tanah. Komposisi keanekaragaman coleoptera dan araneida tanah pada berbagai kondisi sanitasi kebun kakao yang berbeda, menjadi pokok kajian yang dipaparkan dalam tulisan ini. Tujuannya adalah untuk mengevaluasi keanekaragaman dan kerapatan relatif coleopteran dan araneida tanah di berbagai kondisi sanitasi kebun kakao yang berbeda. Di Indonesia tercatat lebih dari 111 spesies Arthropoda merupakan hama, 61 spesies sebagai predator dan 41 spesies adalah parasitoid (Okada et al., 1988). Menurut Settle et al. (1996) perbedaan habitat pada ekosistem pertanian mendukung terjadinya perbedaan komposisi keberadaan fauna tanah termasuk Coleoptera dan araneida. Coleoptera berperan penting dalam ekosistem yakni sebagai predator, herbivor dan sebagai pengurai (Susilo et al., 2009). Selain itu, secara keseluruhan peranan Coleoptera di lahan pertanian sebanyak $40 \%$ dapat mencegah kerusakan tanaman (Borror et al., 1998). Coleoptera termasuk ordo serangga dengan jumlah sebaran yang paling luas, serta beranggotakan lebih dari 750.000 spesies, dan kurang lebih $40 \%$ dari jumlah keseluruhan serangga di dunia (Borror et al., 1992). Coleoptera dapat ditemukan hampir di semua habitat agroekosistem, antara lain di kebun kakao.

Selain Coleoptera, kelompok fauna yang hidup di perkebunan kakao yaitu laba-laba Araneida. Laba-laba terdistribusi di seluruh dunia dan dapat hidup di berbagai ekosistem terrestrial. Laba-laba dapat dijumpai di tempat yang jarang terjangkau oleh manusia seperti di atas pohon, di bawah batu, tepi sungai, rawa bakau, atau pada serasah daun. Kehadiran laba-laba pada suatu lingkungan juga dapat digunakan sebagai pengendali populasi serangga hama pada ekosistem pertanian, karena laba-laba beperan sebagai predator pada beberapa jenis serangga hama, termasuk hama yang menyerang tanaman kakao. Kondisi mikroklimat (habitat) kebun kakao petani di di Sulawesi Tenggara relative bervariasi 
karena adanya perbedaan sanitasi. Perbedaan tipe habitat dapat mempengaruhi keanekaragaman labalaba famili Araneidae, karena secara langsung akan berpengaruh pada kondisi habitat dan sumber daya yang diperlukan oleh laba-laba tersebut. Keragaman dan kerapatan relative Jenis laba-laba yang terdapat di kebun kakao rakyat di Kabupaten Kolaka Timur menjadi kajian penting dalam penelitian ini.

\section{METODE PENELITIAN}

Penelitian ini telah dilakukan pada Bulan Oktober 2014 - Juni 2015 di kebun kakao rakyat dengan empat kondisi sanitasi yang berbeda, yaitu kebun tanpa sanitasi (TS), kebun dengan sanitasi bersih (SB), kebun dengan sanitasi lahan/seresah (SS), dan kebun dengan sanitasi pohon (SP). Alat dan bahan yang digunakan dalam penelitian ini antara lain botol spesimen, insect net, perangkap jebak, light trap, aspirator, dan yellow trap, meteran, tali rafia, termometer, $\mathrm{pH}$ meter, mikroskop, alat tulis, dan buku panduan untuk identifikasi. Metode penelitian yang digunakan adalah deskriptif kuantitatif dengan metode sampling kuadrat, yaitu unit pengambilan sampel berbentuk segi empat yang diletakkan secara sengaja mengikuti pola diagonal di lokasi penelitian. Petak sampling berukuran 10 $\mathrm{m} \times 10 \mathrm{~m}$, masing-masing sebanyak 5 petak untuk setiap kategori sanitasi kebun. Pengukuran faktor fisik lingkungan yaitu suhu udara, kelembaban, intensitas cahaya, dan $\mathrm{pH}$ tanah dilakukan sebelum pengambilan sampel pengamatan berlangsung. Teknik pengambilan sampel:

Pengambilan sampel serangga coleopteran dilakukan melalui beberapa cara yaitu penangkapan langsung menggunakan tangan tanpa alat bantu apapun, jaring serangga, perangkap jebak (pitfall trap), perangkap kuning (yellow trap), dan perangkap cahaya yang dikombinasikan dengan sticky trap, sedangkan untuk koleksi laba-laba, penangkapan dilakukan dengan mencuplik laba-laba yang berada dalam setiap plot dengan menggunakan: 1) Cryptic searching, langsung dengan menggunakan tangan, dilakukan pada habitat yang kemungkinan tersembunyi, misalnya pada serasah, lubang kecil di batang pohon, atau di bawah batu. 2) Sweep netting, yaitu dilakukan dengan menggunakan jaring serangga. 3) Ground hand collecting, yaitu mencuplik sampel yang berada pada permukaan tanah hingga ketinggian sejajar dengan lutut, dan dilakukan untuk menangkap laba-laba yang terlihat pada serasah di atas tanah atau batang pohon. 4) Pitfall trap, yaitu dengan menjebak laba-laba dalam sebuah gelas jebakan yang berisi larutan detergen. Coleoptera dan labalaba hasil koleksi sampel ditempatkan dalam wadah koleksi yang berisi alcohol 
$70 \%$ dan diberi label sesuai waktu dan lokasi pengamatan. Selanjutnya Coleoptera dan laba-laba koleksi dilakukan identifikasi dengan menggunakan buku panduan identifikasi Borror and Delong dan A guide to common singapore spiders, Soil biology guide, dan The fauna of British India including Ceylon and Burma.

Data keanekaragaman

Coleoptera dan Arachnida dianalisis dengan perhitungan indeks keanekaragaman Shannon Wiener dengan rumus $\mathrm{H}^{\prime}=-\Sigma(\mathrm{Pi}$. In $\mathrm{Pi})$, yaitu $\mathrm{H}^{\prime}$ adalah keanekaragaman jenis, dan $\mathrm{Pi}=$ Proporsi nilai penting jenis ke i. Kerapatan relative Coleoptera dan Araneida dihitung menggunakan formula $\mathrm{KR}=\mathrm{KM} / \Sigma \mathrm{KM} \times 100 \% . \mathrm{KM}$ adalah kerapatan mutlak yang nebunjukkan perbandingan antara jumlah individu jenis yang tertangkap dengan jumlah penangkapan.

\section{HASIL DAN PEMBAHASAN}

Ordo Coleoptera dan Araneida merupakan bagia dari hasil penelitian Arthropoda di Ekosistem Kakao rakyat wilayah sentra produksi Sulawesi Tenggara, yaitu Kabupaten Kolaka Timur. Hasil penelitian menunjukkan bahwa, hasil identifikasi serangga ordo Coleoptera diperoleh enam famili yaitu Scarabaeidae, Scolytidae, Staphylinidae, Nitiduli dae, Hydrophilidae, dan Dermestidae, sedangkan dari ordo
Araneida juga diperoleh enam famili yaitu Salticidae, Thomisidae, Araneidae, Lycosidae, Arachnidae, dan Oxyopidae. Tabel 1. menunjukkan bahwa kepadatan relatif tertinggi ordo Coleoptera terdapat di kebun sanitasi bersih, yaitu famili Scolytidae $34,20 \%$, dengan indek keragaman -0.16. Secara keseluruhan, indeks keanekaragaman Coleoptera adalah negative, artinya keragaman jenis dari serangga Coleoptera yang ditemukan di kebun kakao petani rendah untuk semua kategori sanitasi. Nilai indeks kerapatan ordo Coleoptera untuk semua family yang ditemukan di empat kategori sanitasi kebun kakao juga tergolong rendah, yaitu kurang dari $35 \%$. Sanitasi bersih membuat kebun kakao mendapatkan penyinaran cahaya matahari pada daerah kanopi dan sekitar tegakan kakao cukup baik, dan kondisi ini kurang disukai oleh arthropoda, terutama serangga nokturnal yang menggunakan daerah kanopi sebagai tempat berlindung dari sinar matahari langsung, termasuk serangga ordo Coleoptera. Demikian juga permukaan tanah yang bersih dari seresah menyebabkan sinar matahari langsung menyinari permukaan tanah.

Terkait dengan cahaya, ordo Coleoptera umumnya larva dan imago aktif makan dengan habitat yang sama, sehingga keduanya menjadi hama (Jumar, 2000). Cahaya mempunyai peranan penting dalam pertumbuhan, 
perkembangannya dan daya tahan kehidupan serangga baik secara langsung maupun tidak langsung. Cahaya mempengaruhi aktifitas serangga, cahaya membantu untuk mendapatkan makanan, tempat yang lebih sesuai. Namun bagi serangga nocturnal, akan berpindah tempat menuju tempat yang intensitas cahayanya lebih rendah karena aktivitasnya lebih banyak pada waktu dan kondisi intensitas cahaya rendah (malam hari). Setiap jenis serangga membutuhkan intensitas cahaya yang berbeda untuk aktifitasnya.Rendahnya tingkat kerapatan relative Coleoptera disebabkan oleh efek jangka panjang penggunaan pestisida oleh petani dalam budidaya kakao. Populasi serangga akan mengalami perubahan pada awal musim, terutama oleh faktor lingkungan seperti curah hujan, temperatur, dan kelembapan. Coleoptera dan serangga lainnya akan melimpah setelah hujan. Kelembapan atau curah hujan merupakan faktor penting yang mempengaruhi penyebaran, aktivitas, dan perkembangan serangga. Serangga yang memiliki kulit tebal seperti Coleoptera, kandungan airnya lebih rendah. Serangga akan berusaha menyeimbangkan kandungan air dalam tubuhnya untuk bertahan hidup. Kandungan air dalam tubuh serangga bervariasi, umumnya berkisar antara 50$90 \%$ dari berat tubuh. Kelembapan juga berpengaruh pada kemampuan bertelur dan pertumbuhan serangga. Di lapangan, kelimpahan dan perkembangan spesies kumbang scarabid dipengaruhi oleh ph tanah, tanaman penutup dan kepadatan makanan (Kamarudin, dkk, 2005). Serangga sangat sensitif terhadap variasi lingkungan, dan dapat merubah perilakunya dalam merespon perubahan lingkungan. Serangga, khususnya serangga terbang dapat berpindah untuk menghindari perubahan temperatur, kelembapan, zat kimia atau faktor abiotik lainnya yang merugikan (Michael, 1995). Penggunaan pestisida kimia dalam budidaya kakao di lokasi penelitian telah berlangsung lama yaitu sejak tahun 1995. Akibatnya efek residu pestisida di zona permukaan tanah dapat membahayakan kelangsungan hidup organisme Arthropoda permukaan tanah. Kondisi ini dikuatkan oleh Hilszczanski (1997) yang menggunakan keanekaragaman kumbang (Coleoptera) dari kelompok trofik yang berbeda sebagai indikator atas efek jangka panjang aplikasi insektisida pada ekosistem hutan. (Culotta 1996, dalam Alfaro \& Singh, 1997) melaporkan bahwa biodiversitas yang tinggi menyebabkan ekosistem lebih resisten terhadap serangan penyakit dan penyebab kerusakan hutan lainnya yang menurunkan produktivtas primer ekosistem. 
Tabel 1. Kepadatan Relatif Dan Indeks Keanekaragaman Coleoptera di Kebun Kakao Rakyat dengan Berbagai Kondisi Sanitasi

\begin{tabular}{|c|c|c|c|c|c|c|c|}
\hline $\begin{array}{l}\text { Kondisi } \\
\text { Sanitasi }\end{array}$ & Parameter & Scolytidae & Staphylinidae & Scarabaeidae & Dermestidae & Nitidulidae & Hydrophilidae \\
\hline \multirow{3}{*}{$\begin{array}{c}\text { Tanpa } \\
\text { Sanitasi }\end{array}$} & $\mathbf{N}$ & 3.00 & 8.00 & & 3.00 & 12.00 & 5.00 \\
\hline & KR & 22.00 & 12.02 & 9.12 & 2.32 & 6.66 & 2.32 \\
\hline & IK & -0.013 & -0.042 & -0.009 & -0.086 & 0.088 & -0.013 \\
\hline \multirow{3}{*}{$\begin{array}{c}\text { Sanitasi } \\
\text { Bersih }\end{array}$} & $\mathbf{N}$ & 12.00 & 3.00 & 1.00 & 1.00 & 9.00 & 1.00 \\
\hline & KR & 34.27 & 3.25 & 2.24 & 2.12 & 6.72 & 2.36 \\
\hline & IK & -0.16 & -0.05 & -0.01 & -0.02 & 0.10 & -0.01 \\
\hline \multirow{3}{*}{$\begin{array}{l}\text { Sanitasi } \\
\text { Pohon }\end{array}$} & $\mathbf{N}$ & 24.00 & 3.00 & 2.00 & 2.00 & 1.00 & 1.00 \\
\hline & KR & 24.00 & 3.22 & 1.25 & 2.01 & 5.21 & 2.98 \\
\hline & IK & -0.08 & -0.01 & -0.02 & -0.02 & -0.09 & -0.01 \\
\hline \multirow{3}{*}{$\begin{array}{l}\text { Sanitsi } \\
\text { Lahan }\end{array}$} & $\mathbf{N}$ & 4.00 & 1.00 & 1.00 & 1.00 & 11.00 & 1.00 \\
\hline & KR & 18.98 & 1.87 & 2.01 & 1.12 & 1.36 & 2.35 \\
\hline & IK & -0.01 & -0.01 & -0.01 & -0.01 & 0.01 & 0.01 \\
\hline
\end{tabular}

Tabel 1 menunjukkan hal yang sama dengan ordo Coleoptera, nilai keanekaragaman dan kerapatan ordo Araneida atau kelompok laba-laba juga rendah untuk semua kategori sanitasi kebun kakao. Nilai indeks keanekaragamannya negatif dan nilai indeks kerapatannya juga rendah yaitu kurang dari 10\%. Kepadatan relatif tertinggi dari ordo Araneida juga terdapat di kebun sanitasi bersih yaitu famili Lycosidae 5,20\% dengan indek keragaman -0,018. Salticidae dan Lycosidae merupakan laba-laba pemburu yang memiliki mobilitas lebih tinggi dibandingkan laba-laba pembuat jaring. Dengan demikian, kedua famili tersebut mudah ditemukan baik pada tajuk maupun permukaan tanah. Spesies laba-laba predator yang ditemukan di permukaan tanah pada pertanaman kakao ada 11 spesies, yaitu Pardosa pseudoannulata, $\boldsymbol{P}$. sumatrana, $\boldsymbol{P}$. mackenziei, P. oakleyi, Hogna rizali, Araneus inustus, Cylosa insulana, $T$. vermiformis, Runcinia albostriata, Coleosoma octomacula tum, dan Marpisa magister. Laba-laba Famili Lycosidae mendominasi dan ditemukan di permukaan tanah karena laba-laba tersebut memiliki kemampuan mobilitas dan aktivitas tinggi di permukaan tanah (Denno et al., 2004). Selain Lycosidae laba-laba pemburu lainnya adalah Thomisidae, Theridiidae, dan Salticidae. Labalaba pembuat jaring masih ditemukan di permukaan tanah adalah Araneidae dan Tetragnathidae. Kehadiran laba-laba pada suatu ekosistem sangat dipengaruhi oleh faktor lingkungan, seperti suhu, kelembaban, angin, dan intensitas cahaya. 
Tabel 2. Kepadatan Relatif dan Indeks Keanekaragaman Araneida di Kebun Kakao Rakyat dengan Berbagai Kondisi Sanitasi

\begin{tabular}{|c|c|c|c|c|c|c|c|}
\hline $\begin{array}{l}\text { Kondisi } \\
\text { Sanitasi }\end{array}$ & Parameter & Saltisidae & Thomicidae & Araneidae & Oxyophidae & Lyniphidae & Lycosidae \\
\hline \multirow{3}{*}{$\begin{array}{c}\text { Tanpa } \\
\text { Sanitasi }\end{array}$} & $\mathbf{N}$ & 2.00 & 1.00 & 1.00 & 1.00 & 1.00 & 3.00 \\
\hline & KR & 2.50 & 1.36 & 1.39 & 1.21 & 2.77 & 4.98 \\
\hline & IK & -0.02 & -0.01 & -0.04 & -0.01 & 0.01 & -0.02 \\
\hline \multirow{3}{*}{$\begin{array}{l}\text { Sanitasi } \\
\text { Bersih }\end{array}$} & $\mathbf{N}$ & 1.00 & 2.00 & 2.00 & 1.00 & 1.00 & 1.00 \\
\hline & KR & 2.53 & 1.37 & 1.42 & 1.23 & 2.82 & 5.20 \\
\hline & IK & -0.01 & -0.01 & -0.01 & -0.02 & 0.01 & -0.02 \\
\hline \multirow{3}{*}{$\begin{array}{l}\text { Sanitasi } \\
\text { Pohon }\end{array}$} & $\mathbf{N}$ & 2.00 & 1.00 & 2.00 & 1.00 & 1.00 & 3.00 \\
\hline & KR & 2.46 & 1.32 & 1.29 & 1.23 & 2.78 & 2.48 \\
\hline & IK & -0.01 & -0.01 & -0.01 & -0.01 & -0.01 & -0.01 \\
\hline \multirow{3}{*}{$\begin{array}{l}\text { Sanitsi } \\
\text { Lahan }\end{array}$} & $\mathbf{N}$ & 1.00 & 1.00 & 1.00 & 1.00 & 1.00 & 1.00 \\
\hline & KR & 1.15 & 1.02 & 1.23 & 1.01 & 1.01 & 3.26 \\
\hline & IK & -01 & -0.01 & -0.01 & -0.01 & 0.01 & 0.01 \\
\hline
\end{tabular}

Faktor biologis, seperti tipe vegetasi, ketersediaan makanan, pesaing, dan musuh-musuhnya merupakan faktor-faktor yang membatasi kehadiran laba-laba pada suatu ekosistem. Tingginya kelimpahan labalaba pada perkebunan disebabkan oleh melimpahnya serangga hama yang beradadi daerah tersebut. Pada lahan perkebunan selain ditanam tanaman budi daya di sekitarnya juga terdapat tumbuhan lainnya dari famili Asteraceae dan Poaceae. Keberadaan vegetasi bukan-tanaman di sekitar tanaman budi daya juga turut menambah penelitian ini, laba-laba pembuat jaring tersebut ditemukan pada fase pradewasa. Fase pradewasa tersebut dapat diterbangkan oleh angin dan jatuh di permukaan tanah karena mengikuti arah angin, sehingga dapat tertangkap oleh perangkap lubang yang dipasang pada penelitian ini.

\section{UCAPAN TERIMA KASIH}

Pada kesempatan ini penulis menyampaikan ucapan terima kasih kepada bapak Hasbi (Dinas Perkebunan Kab. Kolaka), Bapak A.r. Matta, Bapak Haruna (Perangkat Desa di Ladongi dan Poli-polia), dan Bapak Arnelis dan Bapak Arham (petani kakao) yang telah membantu penulis dalam melakukan penelitian di lapangan. Terima kasih penulis sampaikan kepada Bapak Rony yang telah membantu melakukan identifikasi Arthropoda (Coleoptera dan Laba-laba).

\section{PENUTUP}

\section{KESIMPULAN}

1. Didapatkan 6 (enam) famili dari ordo Coleoptera yaitu Scarabaeidae, Scolytidae, Staphylinidae, Nitidulidae, Hydrophili dae, dan Dermestidae. Kepadatan relatif tertinggi ordo 
Coleoptera terdapat di kebun sanitasi bersih, yaitu famili Scolytidae 34,20\%, dengan indeks keragaman -0.16.

2. Didapatkan 6 (enam) famili dari ordo Araneida yaitu Salticidae, Thomisidae, Araneidae, Lycosidae, Arachnidae, dan Oxyopidae. Kepadatan relatif tertinggi dari ordo Araneida juga terdapat di kebun sanitasi bersih yaitu famili Lycosidae 5,20\% dengan indeks keragaman $-0,018$.

\section{SARAN}

Rendahnya tingkat kepadatan relative dan indeks keanekaragaman Coleoptera dan Araneida menunjukkan bahwa kehidupan biotik di ekosistem kakao lokasi penelitian relative banyak terusik oleh tindakan budidaya kakao yang masih terus menggunakan pestisida kimia yang sudah berlangsung lama, oleh karena itu sebaiknya penggunaan pestisida untuk pengendalian hama dikurangi atau dihentikan dan diganti dengan pestisida hayati yang lebih ramah lingkungan dan berkelanjutan dalam pengendalian organisme pengganggu tanaman kakao.

\section{DAFTAR PUSTAKA}

Anonim, 2002. Musuh Alami, Hama dan Penyakit Tanaman Kakao. Proyek Pengendalian Hama Terpadu Perkebunan Rakyat, Direktorat Perlindungan Perkebunan, Direktorat Jenderal Bina Produksi
Perkebunan - Departemen Pertanian (Edisi Kedua), Jakarta.

Anshary. A., Wahid, A.; dan D. La'lang. 2004. Laporan Survei Jenis Laba-laba Pada Ekosistem Pertanaman Kakao di Sulawesi Tengah. Jurusan Hama dan Penyakit Tumbuhan. Fak. Pertanian Untad.

Borror, D.J., Triplehora C.A., dan Johnson F.N., 1996. Pengenalan Serangga. Penerjemah oleh Soetiyono Partosoedjono, M.Sc. Gadja Mada University Press.

Denno R.F., Mitter M.S., Langellotto G.A, Gratton C., \& Finke, D.L. 2004. Interactions between a hunting spider and a webbuilder : consequences of intraguild predation and cannibalism for prey suppression. Ecol. Entomol. 29(5): 566-577.

http://id.wikipedia.org/wiki/diakses tanggal 19 September 2012.

Jensen, G. L.; W. Lanier dan C. E. Seibert. 1992. Spider identification and management. Montguide. Montana State Uni. Extension service.

http://www.montana.edu/public ations, dikunjungi 9 Agustus 2008.

Jumar, 2000. Entomologi Pertanian. PT. Rineka Cipta, Jakarta.

Kalshowen, L.G.E., 1981. The Pest of Crop in Indonesia Revised and Translated Van Derlan. Ichtiar Baru Van Horen Press. Jakarta.

Kamarudin, N., M. Basri, W., dan Ramle, M., 2005. Environmental Factors affecting the population Density of Oryctes rhinoceros in a Zero-Burn Oil Palm 
Replant. Journal of Oil Palm Research.

Kaston, B. J. 1972. How to Know the Spiders. Wm. C. Brown, Dubuque), including only those groups found in Virginia orchards.

http://www.virginiafruit.ento.vt. edu/spiders.html, dikunjungi 15 Agustus 2008

Lim, G. T. 1992. Biology, ecology, and control of cocoa pod borer, Conopomorpha cramerella pp.85-100. In. Keane P.J. and

Production and Protection C.A.J.

Putter. (eds.) Cocoa pest and
Diseases Management in Sotheast Asia and Australasia. FAO Plant Paper. FAO United Nations. Rome

Michael, P. $1995 . \quad$ Ekologi untuk Penyelidikan Ladang dan Laboratorium. UI-Press. Jakarta.

Tarumingkeng, R. C., 1994. Dinamika Populasi : Kajian Ekologi Kuantitatif. Pustaka Sinar Harapan dan Universitas Kristen Krida Wacana, Jakarta. 